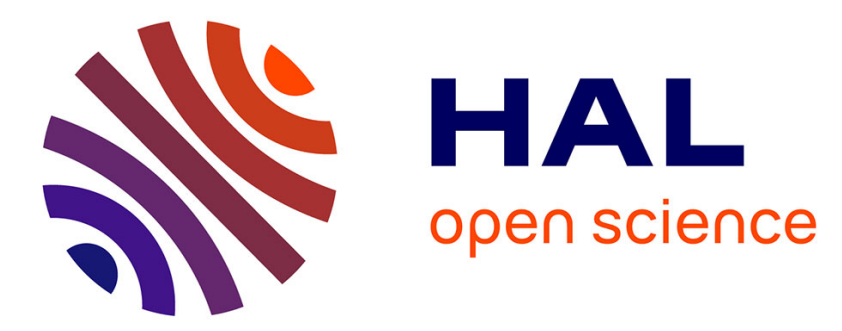

\title{
Morphological and structural study of crystals in black-to-brown glazes of Yaozhou ware (Song dynasty) using imaging and spectroscopic techniques
}

Tian Wang, Clement Hole, Zhao Ren, Pei Zhang, Pei Shi, Jianfeng Zhu, Hongjie Luo, Fen Wang, Philippe Sciau

\section{To cite this version:}

Tian Wang, Clement Hole, Zhao Ren, Pei Zhang, Pei Shi, et al.. Morphological and structural study of crystals in black-to-brown glazes of Yaozhou ware (Song dynasty) using imaging and spectroscopic techniques. Journal of the European Ceramic Society, 2021, 41 (12), pp.6049 - 6058. 10.1016/j.jeurceramsoc.2021.05.025 . hal-03407074

\section{HAL Id: hal-03407074 \\ https://hal.science/hal-03407074}

Submitted on 28 Oct 2021

HAL is a multi-disciplinary open access archive for the deposit and dissemination of scientific research documents, whether they are published or not. The documents may come from teaching and research institutions in France or abroad, or from public or private research centers.
L'archive ouverte pluridisciplinaire HAL, est destinée au dépôt et à la diffusion de documents scientifiques de niveau recherche, publiés ou non, émanant des établissements d'enseignement et de recherche français ou étrangers, des laboratoires publics ou privés. 


\title{
Morphological and structural study of crystals in black-to- brown glazes of Yaozhou ware (Song dynasty) using imaging and spectroscopic techniques
}

\author{
Tian Wang ${ }^{a}$, Clement Hole ${ }^{b}$, Zhao Ren ${ }^{a}$, Pei Zhang ${ }^{a}$, Pei Shi ${ }^{a}$, Jianfeng Zhu ${ }^{a}$, Hongjie \\ Luo $^{\mathrm{c}}$, Fen Wang ${ }^{\mathrm{a}^{*}}$, Philippe Sciau ${ }^{\mathrm{b}, \mathrm{a}^{*}}$
}

\begin{abstract}
${ }^{a}$ Institute of Silicate Cultural Heritage, School of Material Science and Engineering, Shaanxi Key Laboratory of Green Preparation and Functionalization for Inorganic Materials, Shaanxi University of Science and Technology, Xi'an, 710021 China. ${ }^{\mathrm{b}}$ CNRS, CEMES, Toulouse University, 31055 Toulouse, France.

${ }^{\mathrm{c}}$ Shanghai University, Shanghai, 200444 China.

E-mail:wangf@sust.edu.cn; philippe.sciau@cemes.fr
\end{abstract}

\begin{abstract}
:
The Yaozhou kiln complex (Shaanxi, China) is a famous black-to-brown ceramic production center due to its significant volume of production, long manufacturing history (from Tang Dynasty to Yuan Dynasty) and variety of decorations. In this work, four representative types of black-to-brown ware from the Yaozhou kilns were selected to study the morphology, structure and distribution of the precipitated crystals in the glazes using a series of imaging and analytical techniques (optical microscopy, XRF, SEM-EDS, TEM-EDS, $\mu R S$ and UV-Vis-IR). The results show that the rare metastable $\varepsilon-\mathrm{Fe}_{2} \mathrm{O}_{3}$ phase, already observed in typical sauce glaze, was also detected in other types of brown glaze decorations, such as light brown stripes on a darker background or irregular brown spots on a black background. Cross-section analyses also showed a three wellseparated layered crystalline distribution in the glazes of lighter brown colors as it has been noted in glazes from Qilizhen kilns. Raman analyses revealed that the crystals contained in third layer are of varying nature: $\varepsilon-\mathrm{Fe}_{2} \mathrm{O}_{3}$ in the sauce glaze and magnetite in the light brown stripes. The peak shifts and line broadenings observed in the Raman spectra of $\varepsilon-\mathrm{Fe}_{2} \mathrm{O}_{3}$ crystals were also investigated. They are the result of $\mathrm{Al}, \mathrm{Ti}$ and $\mathrm{Mg}$ substitutions, which were identified using TEM-EDS. Such ionic substitutions would stabilize the metastable $\varepsilon-\mathrm{Fe}_{2} \mathrm{O}_{3}$ crystals by increasing the cationic disorder. In addition, Mg-, Ca- and Fe-rich spinel crystals were observed for the first time in a black glaze of Yaozhou wares.
\end{abstract}

Keywords: Yaozhou kilns, Brown glaze, Microstructure, Raman microscopy, $\varepsilon-\mathrm{Fe}_{2} \mathrm{O}_{3}$ 


\section{Introduction}

Black-to-brown ware, which encompasses all ceramics with iron-colored glazes displaying different shades of brown and black, played and still plays an important role in the Chinese ceramic history [1]. From current knowledge, the first black-to-brown glazed ceramics were manufactured during the Eastern Han Dynasty (AD 25-220) in the Yue kiln complex (Zhejiang province). Throughout the following periods, they experienced major technological advances to reach what is considered as their maturity under the Song Dynasty (AD 960-1279) [2,3]. During the Song period, almost every Chinese kiln complex produced at least some black-to-brown wares. In addition to the famous Southern Jian kilns (Fujian province), several northern complexes, such as Pingding kilns, Jiexiu kilns (Shanxi province), Cizhou kilns, Ding kilns, Peicheng kilns, Dangyangyu kilns (Hebei province) or Yaozhou kilns (Shaanxi province) also manufactured various types of blackto-brown ware [4]. One of the most representative kiln complex is Yaozhou: famous for its northern celadon production, this site also manufactured great quantities of black-tobrown ware from Tang to Yuan Dynasty $[5,6]$.

In spite of the large production of black-to-brown glazes, they were relatively under studied in comparison with celadon or blue-and-white porcelain for instance. Orvar Karlberk [7] first found that the plain brown glaze (commonly referred to as sauce glaze) is composed of a surface brown layer sitting on an underlying black layer. Zhang et al. [8] reported that this brown surface layer contains dendritic hematite $\left(\alpha-\mathrm{Fe}_{2} \mathrm{O}_{3}\right)$ and magnetite $\left(\mathrm{Fe}_{3} \mathrm{O}_{4}\right)$ crystals using optical microscopy and laboratory XRD. These crystals, associated with maghemite $\left(\mathrm{Y}-\mathrm{Fe}_{2} \mathrm{O}_{3}\right)$, were reported in other types of black-to-brown wares, such as plain black glaze, hare's fur glaze, oil spot glaze and tea dust glaze [811]. These studies mainly based on laboratory XRD, the results of which were consistent, formed the basis of knowledge about black-to-brown ceramics and were not much complemented with additional studies for decades. However XRD patterns obtained in laboratory can be hard to interpret because of the intense background coming from the glassy matrix, which makes the process of identifying minor crystalline phases much harder. In a 2014 study based on synchrotron radiation micro-XRD combined with Raman spectroscopy, Dejoie et al. showed that the dendritic crystals found in the oil spot patterns of Jian ware were not hematite as previously reported, but in fact the metastable $\varepsilon-\mathrm{Fe}_{2} \mathrm{O}_{3}$ polymorph, which Raman spectrum was also identified for the first time [12]. Since this discovery, this ferric oxide was identified in several types of Chinese glazes, such as in the colored wares from Changsha kilns (Tang Dynasty) [13], purple-gold wares from the Jingdezhen kilns (Qing Dynasty) [14], brown ware from the Ding kilns (Song Dynasty) [15], sauce wares from the Yaozhou [16] and Qilizhen kilns (Song Dynasty) [17]. The presence of $\varepsilon-\mathrm{Fe}_{2} \mathrm{O}_{3}$ crystals in these glazes opens up interesting perspectives, not only in the field technical history of ancient ceramics, but also in the field of modern materials science with the synthesis of pure $\varepsilon-\mathrm{Fe}_{2} \mathrm{O}_{3}[18]$.

To our knowledge, the crystalline organization of $\varepsilon-\mathrm{Fe}_{2} \mathrm{O}_{3}$ polymorph was studied in detail in examples of sauce glaze (Yaozhou kilns and Qilizhen kilns), purple-gold glaze (Jingdezhen kilns) and oil spot and hare's fur glazes (Jian kilns). The existence of $\varepsilon$ $\mathrm{Fe}_{2} \mathrm{O}_{3}$ phase in other types of brown-to-black glazes, which also contain Fe-bearing crystals, still remains to be verified. 
In this work, four fragments representative of different types of black-to-brown wares from the Yaozhou kilns were selected. The morphology of the precipitated crystals, their structure and distribution in the glazes were studied using imaging and spectroscopic techniques (optical microscopy, XRF, SEM-EDS, TEM-EDS, $\mu R S$ and UV-vis-IR). $\varepsilon$ $\mathrm{Fe}_{2} \mathrm{O}_{3}$ crystals were identified not only in the roughly homogeneous in color sauce glaze, but also in other types of black-to-brown glazes, such as brown glaze with decorations, plain black glaze and black glaze with brown spots.

\section{Experimental details}

\subsection{Sample descriptions}

Four fragments of black-to-brown ceramic produced in the Yaozhou kilns (referenced BG-01, BG-02, BG-03 and BG-04) were selected and are shown in Fig. 1. They were excavated from the Huangpu archaeological site of Tongchuan town (Shaanxi province) and provided by the Yaozhou kiln museum. All the samples are dated from the Northern Song dynasty (960-1127 AD) according to the archaeological layer they were found in.

They present brown colors of different shade (from light to dark brown) and tint (sauce to black hue). BG-01 has a homogeneous glossy brown glaze, which is typically referred to as "sauce glaze". Its color is very similar to persimmon, which explains why it is also locally known as "persimmon glaze" [6]. BG-02 has a dark brown glaze with lighter stripes, the latter being called sauce decoration [6]. This is another typical representative Yaozhou brown-to-black ware production. BG-03 has a black and thick outer glaze while its inner glaze is dark brown and relatively thin. The inner surface also presents topography peculiarities probably due to the hand casting process. BG-04 has a brownspotted dark glaze (Fig. 1 enlarged insert map) and homogeneous brown glaze surrounding the foot.

In order to investigate the depth of the glaze, cross-sections of each fragment was made following the preparation method described in detail in reference [19].

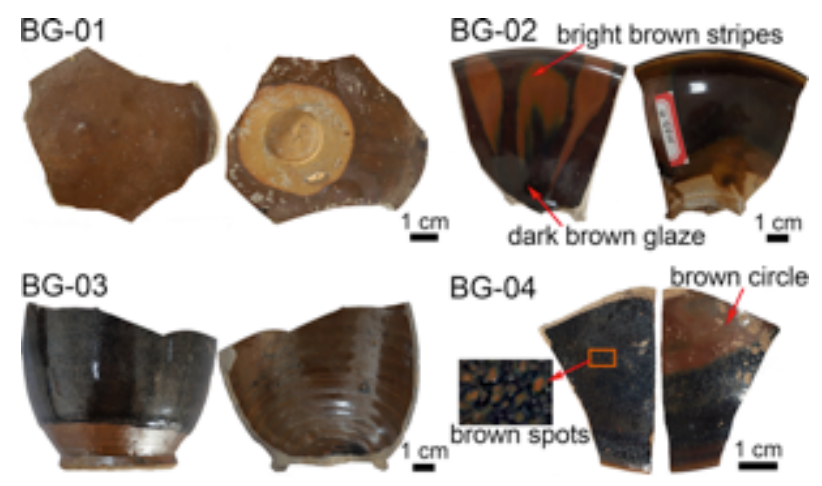

Figure 1 Photos of the four analyzed samples from Yaozhou kiln site (Song Dynasty).

\subsection{XRF quantitative analyses}

X-ray fluorescence (XRF) was operated using a spectrometer from HORIBA XGT$7200 \mathrm{~V}$, Japan at $50 \mathrm{kV}-1 \mathrm{~mA}$, with a beam size of $1.2 \mathrm{~mm}$ diameter. The resolution was $138.3 \mathrm{eV}$ at $\mathrm{Mn} \mathrm{K}_{\alpha}$ line. Spectra were recorded during approximately $120 \mathrm{~s}$ directly at the surfaces of the samples. Spectra of the sample bodies were acquired, as well as spectra of the glaze of BG-01, the dark brown glaze and the lighter stripe of BG-02, the outer 
black and the inner brown glazes of BG-03, the brown-spotted black glaze and the brown glaze near the foot of BG-04. Three measurements were performed on each zone in order to estimate their homogeneity. Spectra retraction and analysis were implemented using XGT-7200 software equipped with the instrument.

\subsection{Imaging techniques}

\subsubsection{Optical microscope analyses}

Optical imaging of the surfaces of each fragment was performed using a KEYENCE optical microscope equipped with a surface depth observation system (VHX-7000). Images were taken with a magnification range from $\times 20$ to $\times 2500$. Ring and coaxial light sources were applied to observe the surface coloration and particle distribution in the glazes of the samples.

\subsubsection{SEM-EDS analyses}

Prior to the analyses, the selected samples (both surface glazes and cross-sections) were coated with a thin layer of platinum to enhance their conductivity. The morphological and elemental analyses of the glaze were conducted using a FEI Apreo LoVac scanning electron microscope (SEM) equipped with an EDAX Octane Elect Super energy dispersive X-ray spectrometer (EDS). Punctual elemental analyses were performed with a beam size of about $0.2 \mu \mathrm{m}$ and quantified afterwards thanks to internal standards.

\subsubsection{TEM-EDS analyses}

Prior to the analyses, two thin sections of sample BG-01 were prepared by "Lift-out" technique [20,21] and fixed on a copper grid using a Helios NanoLab 600i focused ion beam (FIB)-SEM from Thermofisher equipped with a Ga ion source. Elemental analyses were performed using a CM20FEG scanning transmission electron microscope (STEM) from Philips equipped with a Brücker SDD EDS detector. EDS analyses and elemental mapping were recorded at $200 \mathrm{kV}$ at magnification ranging between 50000 and 150000 and data was processed using the Esprit 1.9 software.

\subsection{Spectroscopic techniques}

\subsubsection{Raman spectroscopy analyses}

Raman investigations were mainly performed using a Renishaw inVia spectrometer from Renishaw. Raman excitation was provided by a cw 532-nm solid state laser. The laser spot size was around 2-3 $\mu \mathrm{m}$ diameter. Laser power of $1.31 \mathrm{~mW}$ at $\mathrm{x} 100$ magnification was employed to analyze crystals in the glaze surface and cross-section, to optimize the signal/background ratio and avoid any thermal influence on the crystal spectrum. Spectra were recorded in the $100-2000 \mathrm{~cm}^{-1}$ range.

To assess the impact of crystalline orientation on the Raman spectra, spectra were also recorded using an XploRA spectrometer from Horiba. Raman excitation at $532 \mathrm{~nm}$ was provided by a vertically-polarized DPSS (Diode Pumped Solid State) Nd-YAG laser. Spectra were recorded in the $50-1730 \mathrm{~cm}^{-1}$ range. Spectra were recorded on a crystal tilted of $-20^{\circ}, 0^{\circ},+30^{\circ},+65^{\circ},+125^{\circ},+160^{\circ}$ and $+220^{\circ}$ from its initial position. 


\subsubsection{UV-vis-NIR spectroscopy analyses}

Diffuse reflectance ultraviolet-visible-near-infrared spectroscopy (UV-vis-NIR) was performed using a Cary 5000, Varian, Palo Alto, USA spectroscope operated at room temperature. The reflectance spectra were collected from 200 to $800 \mathrm{~nm}$ (UV-vis) and 800 to $2000 \mathrm{~nm}$ (NIR) with a beam size of $0.6 \mathrm{~mm}$. The spectra were analyzed with the Cary WinUV software supplied with the instrument. The measurements were operated directly at the surface of ceramic fragments on the zones previously analyzed by XRF. To make comparison with the UV-vis and NIR absorption spectra easier, the diffuse reflectance measurements were converted into absorption using the Kubelka-Munk remission function defined by $f(R)=(1-R)^{2} / 2 R$ ( $R$ is the reflectance). Data manipulation was carried out using the Origin software.

\section{Results and discussion}

\subsection{Global Elemental composition}

The elemental compositions of the glazes measured by XRF are given in Table 1. The results are consistent with Yaozhou black-to-brown productions with $\mathrm{SiO}_{2}, \mathrm{Al}_{2} \mathrm{O}_{3}$ and $\mathrm{Fe}_{2} \mathrm{O}_{3}$ in the range of $63-71 \%, 14-19 \%$ and $4-8 \%$ respectively $[6,22]$. The $\mathrm{Al}_{2} \mathrm{O}_{3} / \mathrm{SiO}_{2}$ ratios are generally around 0.25 , except for the BG-01 (0.30-0.31) and the inner brown glaze of BG-03 (0.28-0.31). However the smaller thickness of the inner-glaze of BG-03 may explain this higher ratio, as the $\mathrm{Al}_{2} \mathrm{O}_{3}$-richer body of the ceramic piece (c. $33 \%$, Table S1) could have been in the relatively high interaction volume of XRF during the measurement.

\begin{tabular}{|c|c|c|c|c|c|c|c|c|c|c|c|}
\hline Sample & Glaze & $\mathrm{Na}_{2} \mathrm{O}$ & $\mathrm{MgO}$ & $\mathrm{Al}_{2} \mathrm{O}_{3}$ & $\mathrm{SiO}_{2}$ & $\mathrm{~K}_{2} \mathrm{O}$ & $\mathrm{CaO}$ & $\mathrm{TiO}_{2}$ & $\mathrm{MnO}_{2}$ & $\mathrm{Fe}_{2} \mathrm{O}_{3}$ & $\begin{array}{l}\mathrm{SiO}_{2} / \\
\mathrm{Al}_{2} \mathrm{O}_{3}\end{array}$ \\
\hline \multirow{3}{*}{ BG-01 } & \multirow{3}{*}{$\begin{array}{l}\text { Sauce } \\
\text { glaze }\end{array}$} & 0.49 & 2.68 & 19.13 & 62.85 & 4.08 & 3.17 & 1.25 & 0.07 & 7.09 & 0.30 \\
\hline & & 0.72 & 1.52 & 19.38 & 63.62 & 4.00 & 3.23 & 1.24 & 0.07 & 7.00 & 0.30 \\
\hline & & 0.23 & 1.32 & 19.85 & 64.37 & 4.04 & 3.16 & 1.23 & 0.06 & 6.73 & 0.31 \\
\hline \multirow{6}{*}{ BG-02 } & \multirow{3}{*}{$\begin{array}{l}\text { Bright } \\
\text { brown } \\
\text { stripes }\end{array}$} & 1.07 & 3.30 & 14.26 & 64.01 & 3.35 & 5.59 & 0.69 & 0.09 & 8.54 & 0.22 \\
\hline & & 0.07 & 1.59 & 16.37 & 68.02 & 3.80 & 4.19 & 0.69 & 0.06 & 5.93 & 0.24 \\
\hline & & 0.29 & 0.87 & 19.04 & 66.54 & 4.02 & 3.97 & 0.80 & 0.05 & 5.06 & 0.29 \\
\hline & \multirow{3}{*}{$\begin{array}{c}\text { Dark } \\
\text { brown } \\
\text { glaze }\end{array}$} & 0.78 & 4.28 & 13.66 & 64.44 & 3.38 & 6.84 & 0.58 & 0.09 & 6.69 & 0.21 \\
\hline & & 0.60 & 4.08 & 14.03 & 64.74 & 3.18 & 6.85 & 0.58 & 0.08 & 6.60 & 0.22 \\
\hline & & 0.48 & 3.80 & 14.48 & 65.63 & 3.20 & 6.29 & 0.61 & 0.08 & 6.19 & 0.22 \\
\hline \multirow{6}{*}{ BG-03 } & \multirow{3}{*}{$\begin{array}{l}\text { Inner } \\
\text { brown } \\
\text { glaze }\end{array}$} & 0.01 & 2.09 & 18.58 & 65.43 & 3.47 & 4.88 & 1.17 & 0.06 & 5.11 & 0.28 \\
\hline & & 0.61 & 1.40 & 19.85 & 63.63 & 3.47 & 5.22 & 1.30 & 0.05 & 5.24 & 0.31 \\
\hline & & 0.01 & 2.12 & 18.54 & 64.96 & 3.48 & 4.81 & 1.36 & 0.06 & 5.46 & 0.29 \\
\hline & \multirow{3}{*}{$\begin{array}{l}\text { Outer } \\
\text { black } \\
\text { glaze }\end{array}$} & 0.28 & 2.37 & 13.53 & 69.37 & 3.50 & 5.38 & 0.86 & 0.07 & 5.29 & 0.20 \\
\hline & & 0.77 & 2.86 & 10.86 & 71.83 & 3.47 & 5.06 & 0.56 & 0.07 & 5.20 & 0.15 \\
\hline & & 0.01 & 3.50 & 13.36 & 66.88 & 3.48 & 6.57 & 0.82 & 0.08 & 5.97 & 0.20 \\
\hline \multirow{6}{*}{ BG-04 } & \multirow{3}{*}{$\begin{array}{c}\text { Brown } \\
\text { circle }\end{array}$} & 0.93 & 2.64 & 17.62 & 63.41 & 3.85 & 4.30 & 1.17 & 0.09 & 6.98 & 0.28 \\
\hline & & 0.28 & 3.13 & 16.88 & 64.26 & 3.54 & 4.19 & 1.17 & 0.09 & 7.30 & 0.26 \\
\hline & & 1.43 & 3.38 & 16.88 & 62.53 & 3.58 & 4.39 & 1.16 & 0.09 & 7.42 & 0.27 \\
\hline & \multirow{3}{*}{$\begin{array}{l}\text { Black } \\
\text { glaze }\end{array}$} & 0.01 & 2.13 & 16.80 & 68.15 & 3.55 & 4.31 & 0.74 & 0.08 & 4.98 & 0.25 \\
\hline & & 0.68 & 2.67 & 16.75 & 67.72 & 3.41 & 4.21 & 0.68 & 0.07 & 4.51 & 0.25 \\
\hline & & 0.56 & 3.20 & 16.62 & 67.01 & 3.37 & 4.53 & 0.69 & 0.08 & 4.67 & 0.25 \\
\hline
\end{tabular}

Table 1 Analytical results (wt\%) obtained by X-ray fluorescence on the surfaces of glazes of four samples (BG-01, BG-02, BG-03, BG-04). Three analyzed points were carried out in each area to estimate the homogeneity. 
The glaze of $\mathrm{BG}-01$ has a higher $\mathrm{K}_{2} \mathrm{O}$ and a lower $\mathrm{CaO}$ concentration compared to the other samples. The concentrations of the main coloring elements ( $\mathrm{Ti}$ and $\mathrm{Fe}$ ) vary relatively little between glazes. In general brown glazes have higher $\mathrm{TiO}_{2}$ and $\mathrm{Fe}_{2} \mathrm{O}_{3}$ concentrations than black glazes, which is consistent with previous study [8].

\subsection{Morphological analyses}

The glaze of BG-01 (Fig. S1a) is roughly homogeneously brown in color with many large particle clusters. Optical examination under X2000 magnification (Fig. S1b) and SEM-imaging (Fig. 2a) shows that these clusters are composed of a big globular particle surrounded by dendritic crystals of about ten microns. On the other hand the homogeneous areas contain very smaller light-reflecting crystals, which revealed to be smaller dendrite crystals of 2-3 microns homogeneously distributed in the whole glaze according to SEM-imaging (Fig. 2b).

Fig. S2 highlights the significant color difference between the bright brown stripes and darker background of the BG-02 glaze (Fig. S2a). Bubbles with sizes varying from a few to about sixty microns in diameter were observed in the dark brown glaze under x200 magnification (Fig. S2b) but no particle was found. On the contrary, large particle clusters similar to the one observed on BG-01, as well as small brown crystals were found in the lighter stripes (Fig. S2c). They have a dendritic structure and are homogeneously distributed across the stripe and with sizes varying from a few to about ten microns (Fig. S2d and Fig. 2c).

The outer black glaze of BG-03 contains irregular brown particles (Fig. S3a), which are composed of crystals ranging from several to tens of microns (Fig. S3b), which can be classified as two types according to the differences of their colors under coaxial light: bright white or multicolored. They seem to have different shapes, which is verified with SEM-imaging (Fig. $2 \mathrm{~d}$ and e): the bright white crystals are dendrites and the multicolored ones triangles. The inner brown glaze is rich in bubbles with size varying from several to ca. forty microns (Fig. S3c) and contains shining crystals distributed heterogeneously (Fig. S3d). The crystals are irregular in shape and size, varying from micrometric crystals to two-dimensional dendritic structures of about 3-4 $\mu \mathrm{m}$ (Fig. 2f) or highly organized dendritic structures of about 6-7 $\mu \mathrm{m}$ (Fig. $2 \mathrm{~g}$ ).

The brown glaze near the foot of BG-04 (Fig. S4a) has a similar morphology to the brown stripes of BG-02 (Fig. S2c), with clearly visible dendritic crystals of about ten microns (Fig. 2i and S4b). Globular crystals surrounded by dendritic crystals of about ten microns, such as those found in BG-01 were also observed in this area (Fig. 2h). The brown spots on the dark glaze were found to contain many small shining crystals (Fig. S4d) of irregular shape with sizes averaging around one micron (Fig. 2j).

To complement these surface analyses, SEM-imaging was performed on crosssections. Fig. 3a shows that the crystals are distributed in three layers in BG-01 sample. The first layer (Layer 1 ) is close to the surface and continues up to 1-2 $\mu \mathrm{m}$ deep. It contains long crystals and is separated from the second layer (Layer 2) by a crystaldepleted layer of 1-2 $\mu \mathrm{m}$. Layer 2 contains sub-micrometric crystals. Another crystaldepleted layer is found between Layer 2 and 3 . Layer 3 contains crystals larger than the ones found in Layer 2, which decrease in size deeper in the glaze. 


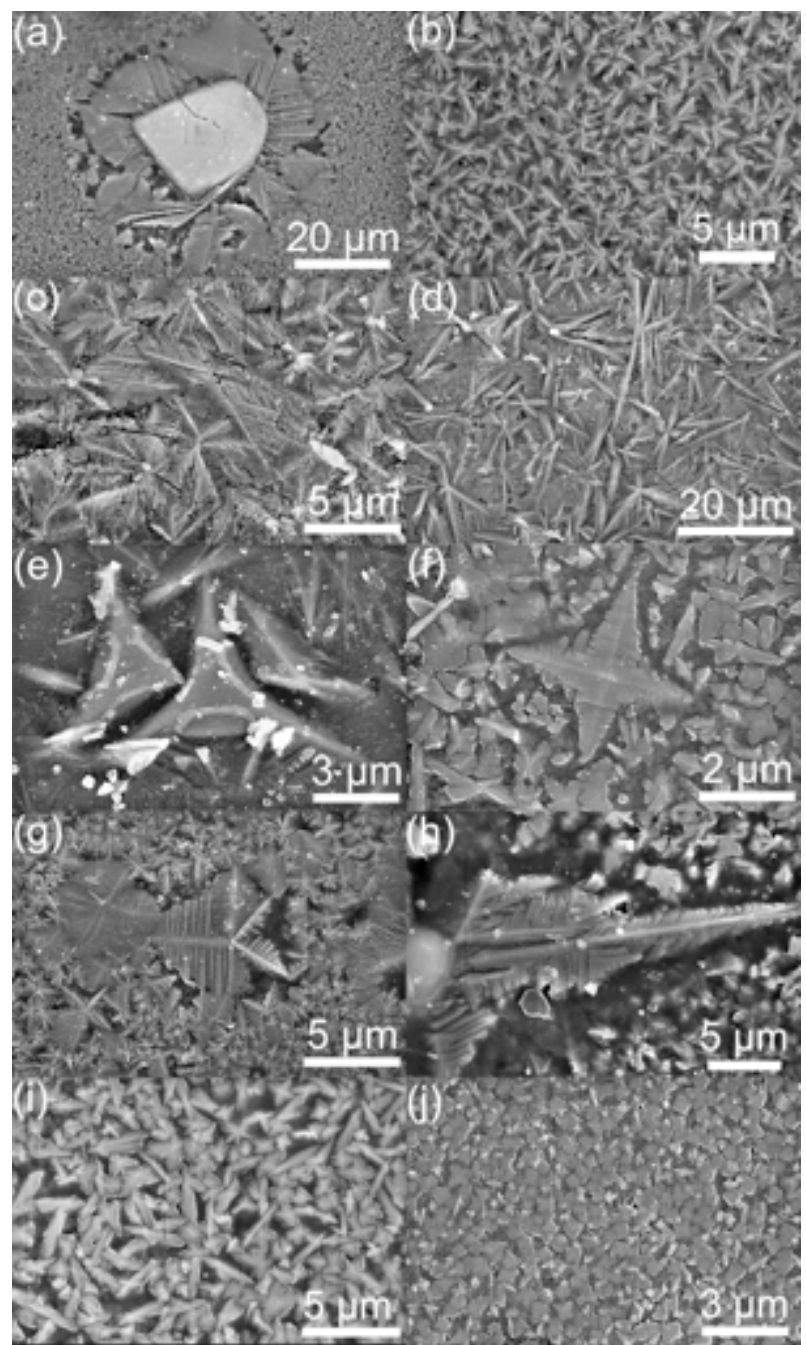

Figure 2 Particles of different shapes in glazes of samples observed by SEM-BSE: (a) and (b) sauce glaze of BG-01; (c) brown stripe decors of BG-02; (d) and (e) outer black glaze of BG-03; $(f)$ and $(\mathrm{g})$ inner brown glaze of BG-03; (h) and (i) brown circle of BG-04; (j) brown spots in black glaze of BG-04.
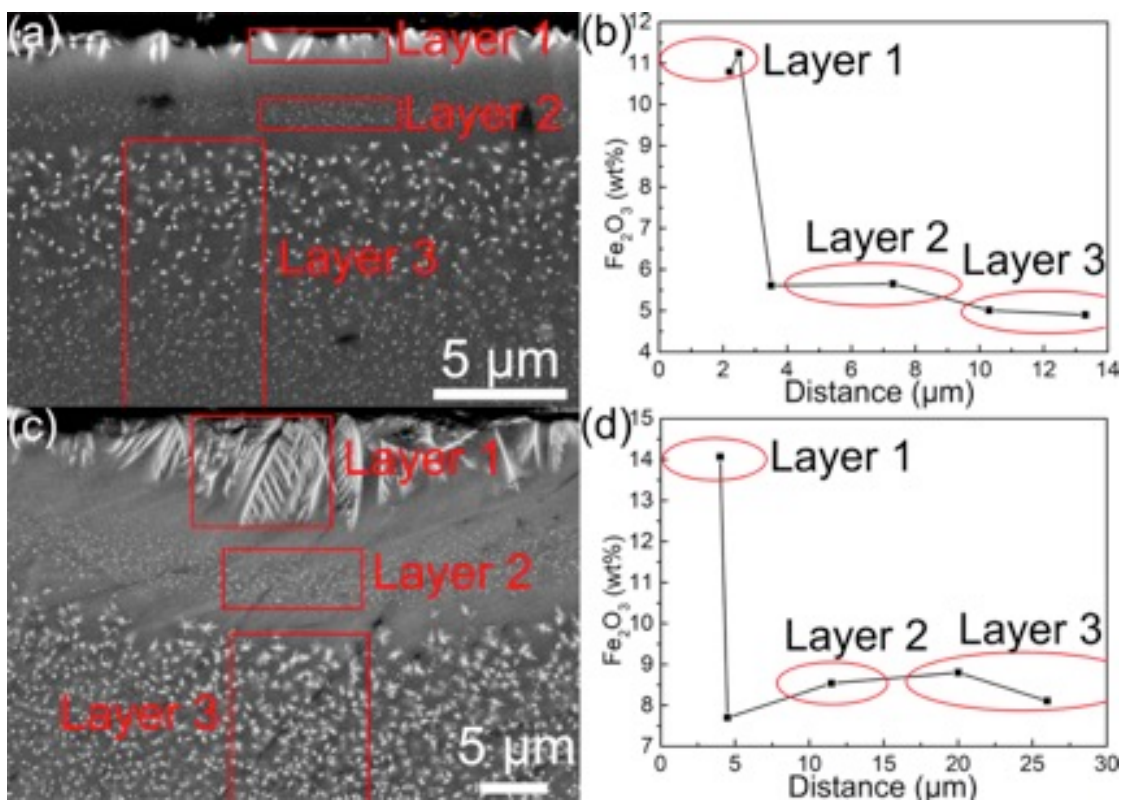

Figure 3 SEM observation of cross-sections of BG-01 (a) and the brown stripe zone of BG-02 (c) and the corresponding iron concentration by EDS ( $b$ and $d)$. 
Similar morphological structures were observed in the brown stripe of BG-02 (Fig. 3c and d), however with respective thicknesses much larger than those of BG-01. Such layered structures were already reported in a study of sauce glaze from Qilizhen kilns [17].

This layered organization was however not observed in the two other samples, which have no sauce glaze zone, and in the darker area of BG-02. There, the crystals are only distributed in one layer at the glaze surface.

\subsection{Characterization of crystalline structures}

A combination of micro-Raman measurements and EDS analyses were performed to precisely identify the various crystals previously described.

The globular crystals found in BG-01 and BG-04 samples (Fig. 2a) contain Si, Zr and O (Fig. 4a) and their Raman spectra are well characteristic of zircon (Fig. 5a). Dendriticshaped crystals (Fig. 2b, Fig. 3a-b, Fig. 3d-g) and irregularly-shaped crystals (Fig. 3h) contain mainly iron according to the EDS analyses (Fig. 4d red curve), the other elements found being very likely to come from the glassy matrix surrounding them. They were both identified as $\varepsilon-\mathrm{Fe}_{2} \mathrm{O}_{3}$ crystals by Raman spectroscopy (Fig. $5 b$ ).

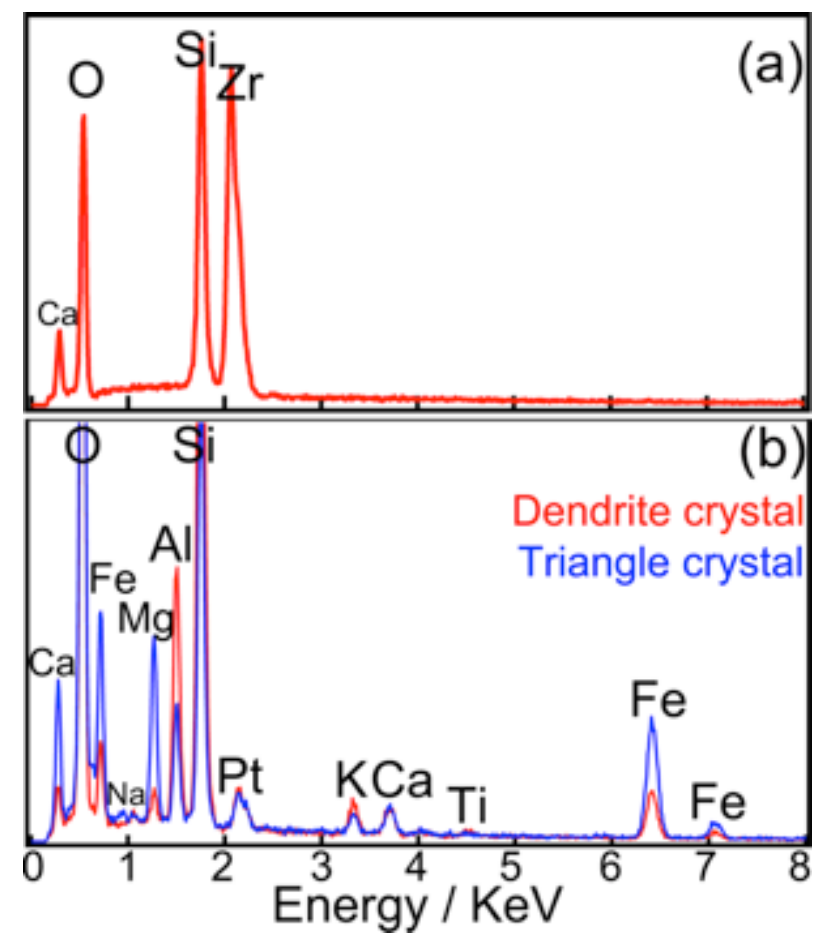

Figure 4 (a) Comparison of the elemental compositions of dendrite crystal (red curve) and triangle crystal (blue curve) in the outer black glaze of BG-03; (b) Representative EDS spectrum of circular particles of tens of microns diameter observed in BG-01.

EDS analyses of the triangle-shaped particles found in the outer black glaze of BG03 (Fig. S3b and Fig. 2e) present less Si and Al and more Ca, Mg and Fe (Fig. 4b blue curve) than those of dendritic crystals (Fig. 4b, red curve). This suggests that they probably contain $\mathrm{Ca}, \mathrm{Mg}$ and $\mathrm{Fe}$. The features of the Raman spectra of these triangle crystals are characteristic of the spinel structure (Fig. 5c). The peaks at 212, 334, 480, 549 and $710 \mathrm{~cm}^{-1}$ could be assigned to the $F_{2 g}, E_{g}, F_{2 g}, F_{2 g}$ and $A_{1 g}$ modes of synthesized 
magnesioferrite respectively, according to the Renishaw minerals and inorganic materials database (abbreviated as RMIM, No. 503, Fig. S5 red curve) and literature [23-25]. Two extra peaks were observed around $612 \mathrm{~cm}^{-1}$ and $668 \mathrm{~cm}^{-1}$, which do not belong to synthesized magnesioferrite but are consistent with natural one, according to the RRuFF database (ID: R070127, Fig. S5 blue curve). Besides, harmunite $\left(\mathrm{CaFe}_{2} \mathrm{O}_{4}\right)$ could also exhibit a Raman feature around $620 \mathrm{~cm}^{-1}$ according to lattice dynamical calculations [26]. This peak could be attributed to the symmetric stretching of oxygen atoms along $\mathrm{Ca}-\mathrm{O}$ bond in the tetrahedral coordination. This would be consistent with the EDS measurements, which revealed the presence of $\mathrm{Ca}$ in these crystals, thus suggesting a partial substitution of $\mathrm{Mg}$ ions by $\mathrm{Ca}$ ions, resulting in a $\left(\mathrm{Mg}_{\mathrm{x}} \mathrm{Ca}_{1-\mathrm{x}}\right) \mathrm{Fe}_{2} \mathrm{O}_{4}$ composition. Unfortunately, Raman study of comparable compounds has not been reported in the literature to our knowledge, which prevents us from going further in the interpretation of the results.
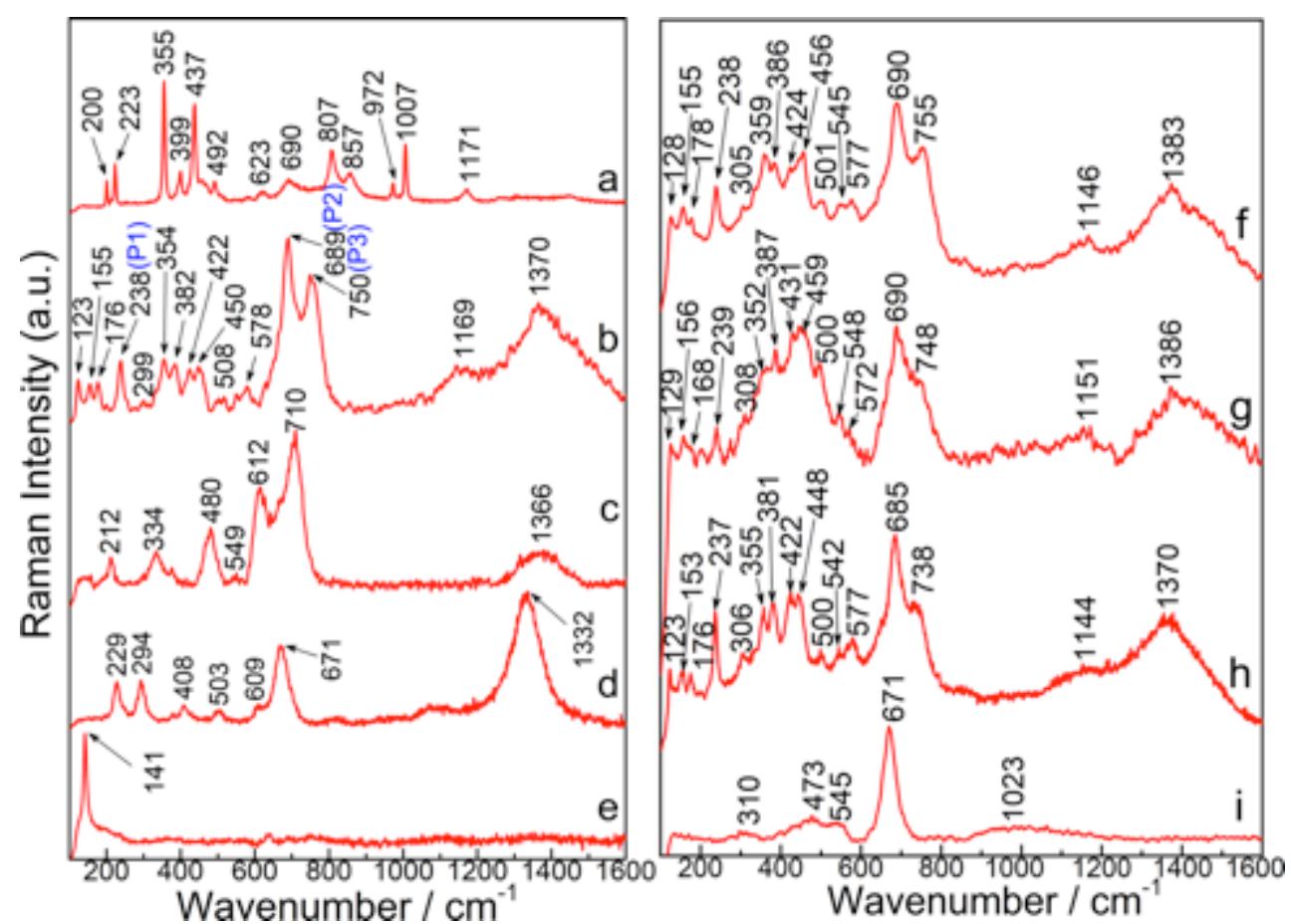

Figure 5 Raman spectra recorded in glaze surfaces of the four samples ((a) zircon, (b) $\varepsilon-\mathrm{Fe}_{2} \mathrm{O}_{3}$, (c) magnesioferrite, (d) hematite, (e) anatase), in the cross-section of BG-01 (analyzed areas are $5 \mu m(f)$ and $19 \mu \mathrm{m}(\mathrm{g})$ away from the glaze surface, respectively) and in the cross-section of BG-02 (analyzed areas are $5 \mu \mathrm{m}(\mathrm{h})$ and $35 \mu \mathrm{m}$ (i) away from the glaze surface, respectively).

Several particles found in the dark brown glaze of BG-02 were identified as hematite according to Raman spectroscopy (Fig. 5d). The additional peak found around $671 \mathrm{~cm}^{-1}$ can be explained by partial substitution of $\mathrm{Fe}$ by $\mathrm{Al}$ and $\mathrm{Ti}$ [27]. A global frequency shift of hematite spectra was also observed (Fig. S6), which are consistent with Fe substitutions. Additionally anatase particles were observed in the brown glaze near the foot of BG-04 (Fig. 5e). The different species detected by SEM-EDS and Raman spectroscopy in the glaze surfaces of four samples (BG-01, BG-02, BG-03, BG-04) are summarized in Table 2. Raman spectroscopy was also performed on the cross sections of BG-01 and BG-02 samples to characterize the crystals found in the different layers. Spectra recorded on the 
crystals found in Layer 2 of BG-01 (Fig. 5f) and BG-02 (Fig. 5h) display the characteristics of the $\varepsilon-\mathrm{Fe}_{2} \mathrm{O}_{3}$ phase, such as the spectra recorded on the crystals found at the surface (Fig. 5b). As for crystals found in Layer 3 (Fig. 3) (19 $\mu \mathrm{m}$ bellow the surface for BG-01 and $35 \mu \mathrm{m}$ for BG-02), some differences were noticed. Crystals in Layer 3 of BG-01 (Fig. 5g) were still identified as $\varepsilon-\mathrm{Fe}_{2} \mathrm{O}_{3}$ although the Raman peaks were broadened [28]. Raman spectra of crystals in Layer 3 of BG-02 display a strong peak at $671 \mathrm{~cm}^{-1}$ and two smaller peaks at 310 and $545 \mathrm{~cm}^{-1}$ (Fig. $5 \mathrm{i}$ ), which can be attributed to the $A_{1 g}, E_{g}$ and $T_{2 g}$ modes of magnetite respectively [29]. Magnetite clusters were also reported in the glaze of a brown Ding ware deep under layers containing only $\varepsilon-\mathrm{Fe}_{2} \mathrm{O}_{3}$ [15]. Two broad peaks are also present at c. 500 and $1000 \mathrm{~cm}^{-1}$ which could be explained with the bending and stretching modes of the $\left[\mathrm{SiO}_{4}\right]^{\mathrm{n}-}$ tetrahedron of the glassy matrix [19].

\begin{tabular}{|c|c|c|}
\hline Sample & Glaze & Crystals \\
\hline BG-01 & Sauce glaze & $\varepsilon-\mathrm{Fe}_{2} \mathrm{O}_{3}$ (major), zircon (minor) \\
\hline \multirow{2}{*}{$\mathrm{BG}-02$} & Bright brown stripes & $\varepsilon-\mathrm{Fe}_{2} \mathrm{O}_{3}$ (major), hematite (minor) \\
\cline { 2 - 3 } BG-03 & Dark brown glaze & basically no crystals, hematite (few) \\
\cline { 2 - 3 } & Inner brown glaze & $\varepsilon-\mathrm{Fe}_{2} \mathrm{O}_{3}$ (major), hematite (minor) \\
\hline \multirow{3}{*}{ BG-04 } & Outer black glaze & $\begin{array}{c}\varepsilon-\mathrm{Fe}_{2} \mathrm{O}_{3} \text { (major), magnesioferrite (major), } \\
\text { hematite (minor) }\end{array}$ \\
\cline { 2 - 3 } & $\begin{array}{c}\text { Brown spots in black } \\
\text { glaze }\end{array}$ & $\begin{array}{c}\varepsilon-\mathrm{Fe}_{2} \mathrm{O}_{3} \text { (major), zircon (minor), anatase } \\
\text { (minor) }\end{array}$ \\
\hline
\end{tabular}

Table 2 Crystal types detected by SEM-EDS and Raman spectroscopy in the glaze surfaces of four samples (BG-01, BG-02, BG-03 and BG-04).
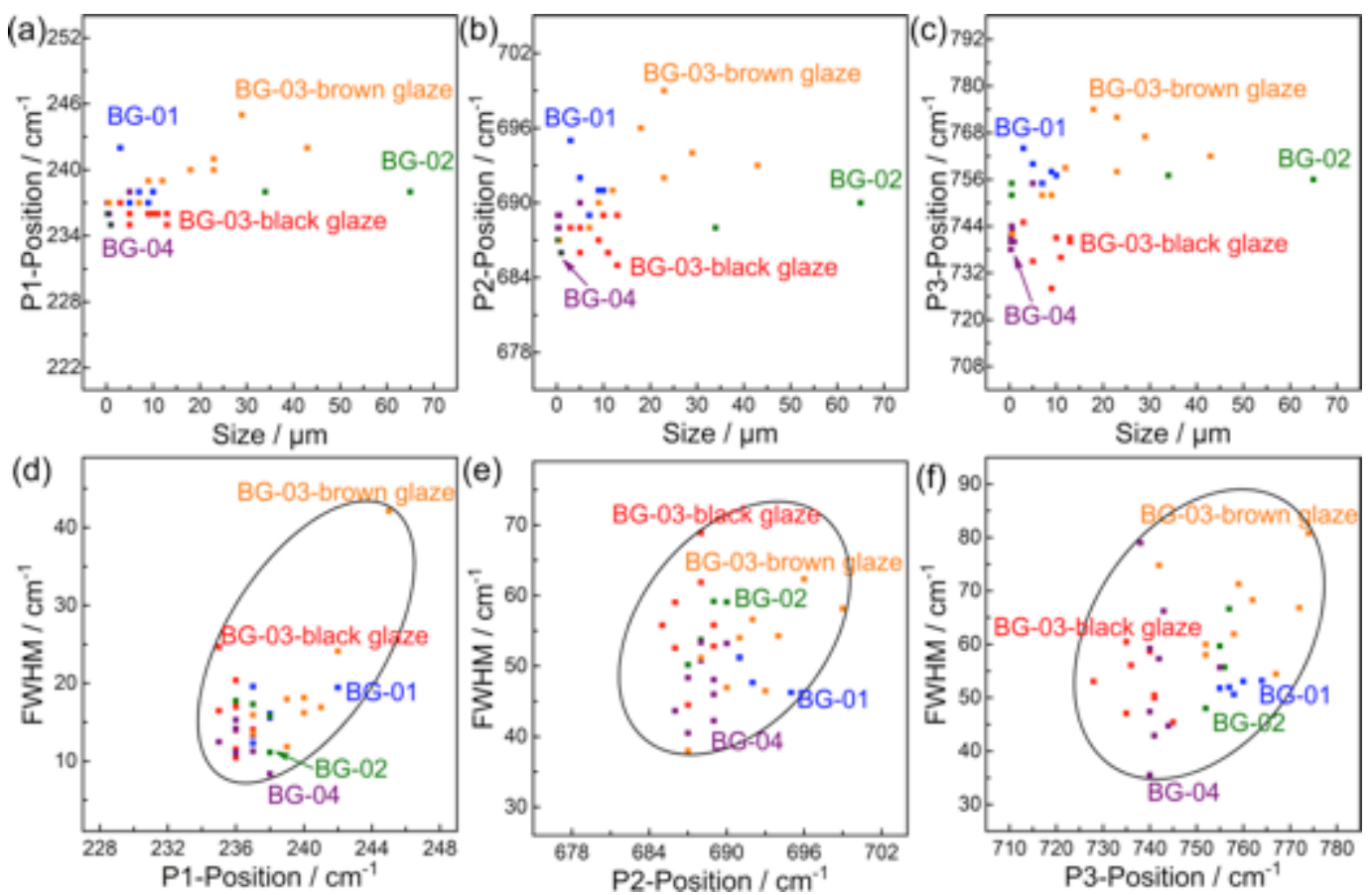

Figure 6 Graphical representations of crystal sizes versus $P 1, P 2$ and $P 3$ peak positions $(a, b$ and $c)$ and the peak positions versus full width at half maximum (FWHM) (d, e and f) for all samples. 
These results suggest that the different color shade between the sauce glaze of BG01 and the light stripes of BG-02 could result in part from the different nature of the crystals present in Layer $3\left(\varepsilon-\mathrm{Fe}_{2} \mathrm{O}_{3}\right.$ for $\mathrm{BG}-01$ and $\mathrm{Fe}_{3} \mathrm{O}_{4}$ for $\left.\mathrm{BG}-02\right)$ in addition to the different thicknesses of these layers.

The investigation of possible structural changes in $\varepsilon-\mathrm{Fe}_{2} \mathrm{O}_{3}$ crystals of different sizes and shapes was also implemented by fitting of the three well-defined peaks (P1, P2 and P3) of the Raman spectra (Fig. 5b blue brackets).

Fig. 6a-c shows that the positions of the three peaks vary from 235 to $245 \mathrm{~cm}^{-1}, 685$ to $699 \mathrm{~cm}^{-1}$ and 727 to $774 \mathrm{~cm}^{-1}$ respectively with varying crystalline sizes. These ranges encompass the positions of the peaks found in previous studies on oil spotted Jian ware [12]. However shift toward higher wave number with increasing crystalline size was observed for crystals in the inner brown glaze of BG-03 and the brown glaze near the foot of BG-04, whereas the contrary is observed for BG-01 and the black glaze of BG-03. In addition the spectra recorded on the bright brown stripes of BG-02 show no significant variation of the peak positions with the crystalline size.

The correlation of the broadening of all peaks with the Raman shift presented in the Fig. 6d-f show a general increase of the broadening with the increase of the Raman shift. However when looking separately at the samples, this correlation is only noticeable in the brown glaze of BG-03.

The shifts and line broadenings of Raman peaks recorded on crystals can generally be attributed to particle size effect [28] or ion substitutions [30]. Crystalline orientation can also influence the Raman spectra [31] by extinguishing some peaks, which can be seen as shifts for structures displaying complex Raman features with many peaks such as $\varepsilon$ $\mathrm{Fe}_{2} \mathrm{O}_{3}$.

In this study, analyzed crystals are micrometric, which makes the effect of the particle size negligible, as it is significant only for crystals in the nanometer to tens of nanometers range. This is confirmed by the absence of coherent trend linking the size of the crystals studied here with the shifts.

Raman spectra recorded on 2D organized $\varepsilon-\mathrm{Fe}_{2} \mathrm{O}_{3}$ crystals of $\mathrm{BG}-01$ at different angles (Fig. S7) show that the broadening and the intensity of the Raman bands indeed varies with the angle, however no significant position shift of P1 $\left(236 \mathrm{~cm}^{-1}\right), \mathrm{P} 2\left(686 \mathrm{~cm}^{-1}\right)$ and P3 $\left(750 \mathrm{~cm}^{-1}\right)$ was observed. This suggests that the peak shifts observed for crystals of different sizes (Fig. 6a-c) is not due to their different orientations.

These results suggest that the peak shifts observed are due to ionic substitution in the $\varepsilon-\mathrm{Fe}_{2} \mathrm{O}_{3}$ crystals. TEM-EDS investigation was implemented on two thin sections of sample BG-01 to verify this hypothesis. One thin section make in a large $2 \mathrm{D}$ organized crystals and another in smaller dendrites in order to compare their composition. Elemental mapping shows that the $2 \mathrm{D}$ organized crystals contain $\mathrm{Al}, \mathrm{Ti}$ and $\mathrm{Mg}$ in addition to $\mathrm{Fe}$ (Fig. 7a) whereas smaller dendrites seem to contain less $\mathrm{Ti}$ and $\mathrm{Al}$ and much less Mg (Fig. 7b). 


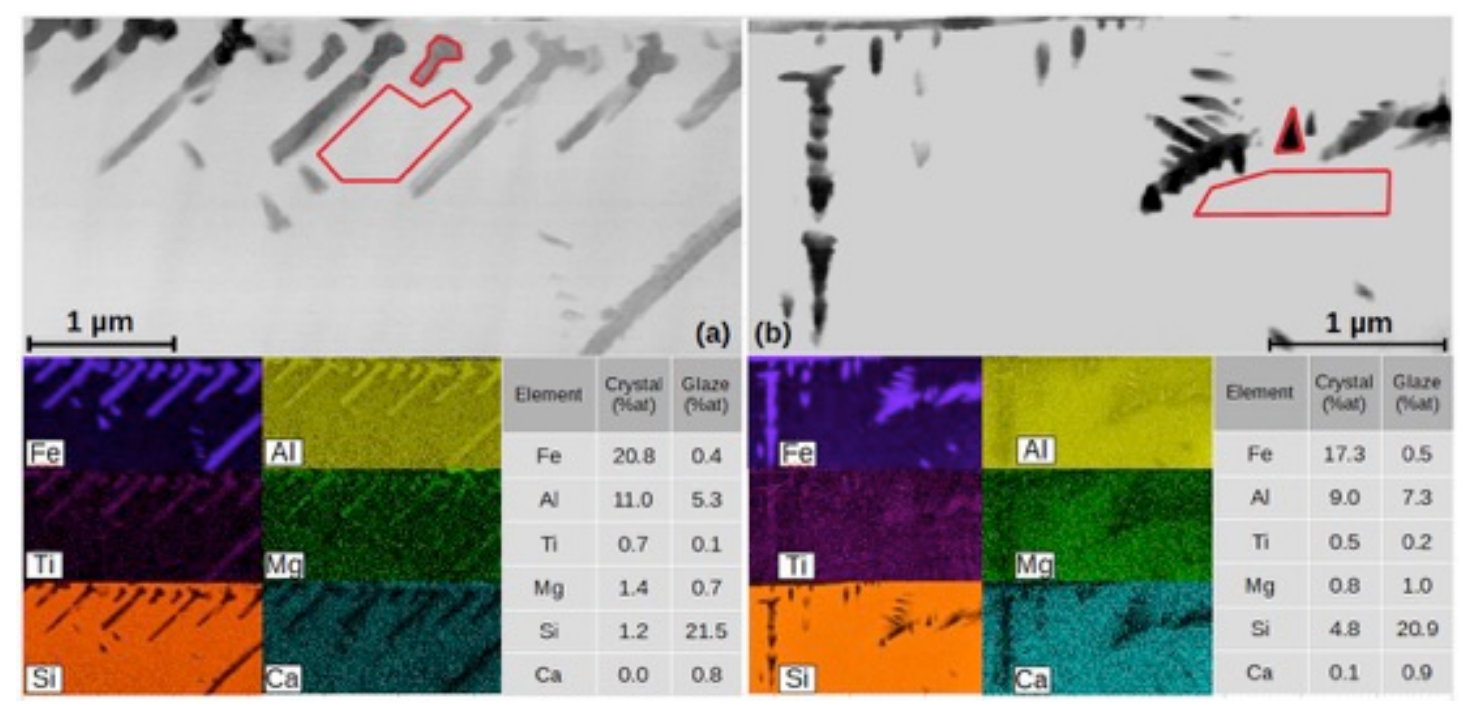

Figure 7 STEM-EDS elemental mapping of thin sections of 2D organized dendrites (a) and smaller dendrites (b) and EDS analysis of a crystal and the near glaze (red areas on the STEM picture).

Percentages given in the composition tables are completed with $\mathrm{O}, \mathrm{K}, \mathrm{Na}, \mathrm{Cr}$ and $\mathrm{Mn}$ to obtain $100 \%$.

To highlight the observed differences, quantitative elemental analyses (atomic \%) on crystals and glaze areas were carried out. The atomic \% of the main elements of interest found on the red areas highlighted in the pictures are given in the tables (Fig. 7), other elements being $\mathrm{O}, \mathrm{K}$ and minor amounts of $\mathrm{Na}, \mathrm{Cr}$ and $\mathrm{Mn}$. Measurements performed on several other crystals and glaze areas gave similar results. They confirm the presence of $\mathrm{Al}, \mathrm{Mg}$ and $\mathrm{Ti}$ in bigger 2D organized crystals (Fig.7a). The smaller dendritic crystals are also $\mathrm{Al}$ and Ti substituted (Fig. $\mathrm{Fb}$ ) and the comparison of $\mathrm{Mg} / \mathrm{Si}$ ratios between the glaze and the crystals show that the latter are also enriched in $\mathrm{Mg}(0.17$ in the crystals $>0.05$ in the glaze), such as the bigger crystals, which seem logical to compensate the excess of charges brought by the Ti ions. In addition it can be noted that the two types of crystals have different substitution rates. It is higher in bigger crystals than in smaller. The difference in composition between both types of crystals is coherent with the Raman observations.

Further investigation using UV-Vis-NIR spectroscopy to compare the absorptive features of the brown and darker areas of the glazes was performed. Since absorption bands situated in the 200 to $800 \mathrm{~nm}$ range give information about the coordination of trivalent iron and the bands in the 800 to $2000 \mathrm{~nm}$ range about coordination of bivalent iron [32], spectra were separated in these two ranges for easier interpretation (Fig. 8 and Fig. 8S).

Fig. 8a displays the UV-vis absorption spectra from 200 to $800 \mathrm{~nm}$ recorded on the brown areas of each sample. Four main absorption bands were detected (labeled bands I, II, III and IV). Band I is broad $(270-350 \mathrm{~nm}$ ) and hard to locate precisely due to the noise and the strong background at the lower wavelength. Band II $(400-450 \mathrm{~nm})$ is visible both in BG-01 and BG-04 can be attributed to a ligand field transition of octahedrally coordinated $\mathrm{Fe}^{3+}$, which is typically observed in the spectra of a wide variety of iron oxides (hematite, maghemite, geothite...) [33,34]. Bands III $(480-450 \mathrm{~nm})$ and IV (625$675 \mathrm{~nm}$ ), the latter being highlighted with second derivative analysis although not obviously visible on the figure, of the four samples can be associated respectively with 
tetrahedral and octahedral coordination of $\mathrm{Fe}^{3+}[33,34]$. The observed absorptive features are consistent with the $\varepsilon-\mathrm{Fe}_{2} \mathrm{O}_{3}$ structure, which contains both tetrahedrally and octahedrally coordinated $\mathrm{Fe}^{3+}$ ions. According to the optical and SEM imaging showing that there are a great proportion of crystals at the surface, the STEM-EDS analysis showing that iron is much more concentrated in the crystals than the glaze and due to the low penetration depth of the beam, the influence of $\mathrm{Fe}^{3+}$ ions in the glassy matrix is low.

Spectra recorded in darker areas of the glaze (Fig. 8b) show three bands (labeled 1, 3 and 6) similar to the band I, III and IV recorded on the brown areas. However other features can be noticed, such as band $2(450-480 \mathrm{~nm})$ in BG-03, band $4(545-590 \mathrm{~nm})$ in BG-02 and band 5 (590-615 nm) of BG-03 and BG-04. Band 2 in particular can be associated to a transition of a Mg-Fe pair of the Mg- and Fe-rich spinel characterized by Raman and EDS analysis. The other bands can be associated to $\mathrm{Fe}^{3+}$ transitions. In the darker areas, much less crystals were observed, making the contribution of $\mathrm{Fe}^{3+}$ ions dispersed in the glassy matrix higher.

The NIR absorption spectra recorded on the samples (Fig. S8) all show similar features: a broad band between 1025 and $1350 \mathrm{~nm}$, which may be two broad bands convoluted together because of the shoulder noticeable around $1200 \mathrm{~nm}$ on few spectra, and a smaller band between 1400 and $1450 \mathrm{~nm}$. They can be attributed to octahedrally coordinated $\mathrm{Fe}^{2+}$ ions [32]. The presence of $\mathrm{Fe}^{2+}$ ions in the glazes of the samples reveals that the glaze vitrified under reducing conditions. However, the presence of the $\mathrm{Fe}^{3+}$-bearing crystals at the surface shows that the cooling was under an oxidizing atmosphere.

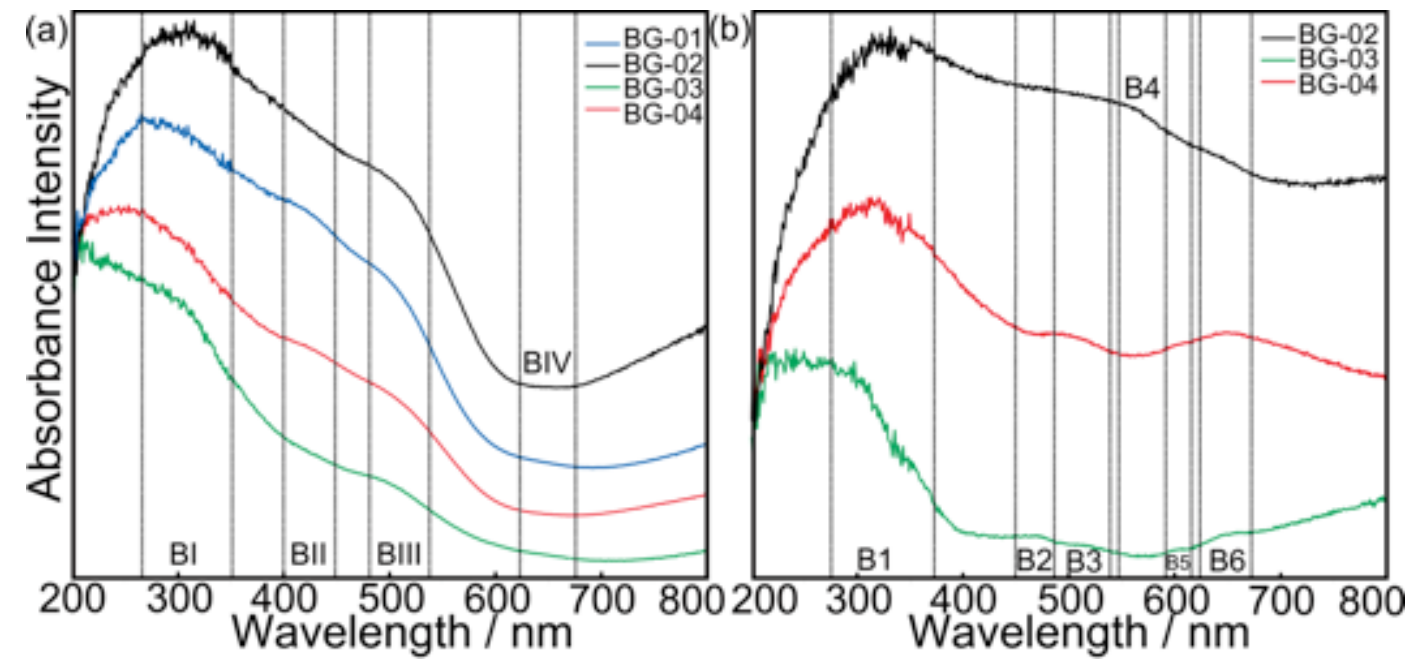

Figure 8 UV-vis spectra with main absorption features of the glaze recorded from 200 to $800 \mathrm{~nm}$ : (a) brown areas of the glazes of BG-01 (blue curve), BG-02 (black curve), BG-03 (Green curve), BG-04 (red curve) and (b) the darker areas of the glazes of BG-02 (black curve), BG-03 (green curve), BG-04 (red curve).

\section{Conclusions}

The rare $\varepsilon-\mathrm{Fe}_{2} \mathrm{O}_{3}$ polymorph was found in the typical sauce glaze sample (BG-01) as well as all the other types of brown-to-black glazes from the Yaozhou kilns studied, such as the brown stripes of the sauce-decorated ware (BG-02), the inner brown glaze of a two-colored brown ware (BG-03) and the brown ring surrounding the foot and the brown spots of a brown-spotted black glaze (BG-04). 
Well-developed dendritic structures were observed in the lighter brown areas of the samples, whereas almost no crystals were observed in the darker areas of BG-02 and irregularly shaped ones were noticed on the dark glaze of BG-03. Cross-section analyses revealed the presence of crystalline-layered structures in BG-01 and the brown stripes of BG-02, similar to those reported in sauce glaze from the Qilizhen kilns [17]. $\varepsilon-\mathrm{Fe}_{2} \mathrm{O}_{3}$ is present in the different layers of BG-01 and the top layers of BG-02, but magnetite was found in the deeper layer of BG-02, as reported in a brown Ding ware [15]. Such structures were not observed on the differently colored samples and the crystals were only in one layer near the surface. Mg-, Ca- and Fe-rich spinel crystals were also detected in irregular brown areas of the outer black glaze of BG-03.

These identifications, coupled with the fact that the glazes are generally brown on the surface and black in depth, suggest that the brown coloration is closely linked with the presence of $\varepsilon-\mathrm{Fe}_{2} \mathrm{O}_{3}$ and the darker color in depth to the presence of magnetite clusters. The shades of brown seem also be related to the different nature, distribution and characteristics of the crystals in the glaze.

Furthermore Raman investigation showed varying peak shifts, which suggested that the $\varepsilon-\mathrm{Fe}_{2} \mathrm{O}_{3}$ crystals of different sizes are stabilized by cationic substitutions. TEM-EDS analyses confirmed the presence of Al-, Mg- and Ti-substitutions in the crystals of the sauce glaze sample.

\section{Acknowledgement}

We warmly thank Dr. Cécile Marcelot from CEMES CNRS, for her essential assistance in the recording of the STEM-EDS data.

This work has been financially supported by China National Key Research and Development Plan (No. 2019YFC1520300), China National Natural Science Foundations (No. 51972201 and No. 51902192) and Shaanxi Natural Science Basic Research Projects (No. 2021JZY-014, No. 2020JQ-721 and No. 2018JQ5071). It was performed in the framework of the research collaboration agreement (CNRS No. 186116) between the French National Centre for Scientific Research and the Shaanxi University of Science and Technology.

\section{References}

[1] J. Li, History of science and technology in China, Ceramics Volume, Science Press, Beijing, 1998.

[2] Z. Ling, A preliminary study on ancient black glazed porcelain in China, J. Chin. Ceram. Soc. 7 (1979) 190-200+283-284.

[3] X. Feng, Histroy of Chinese ceramics, Cultural Relics Publishing House, 1982.

[4] X. Feng, B. Geng, G. Yang, A photo dictionary of Chinese ancient ceramics, Cultural Relics Publishing House, 1998.

[5] X. Chen, J. Zhi, R. Huang, S. Chen, Z. Zhuo, B. Du, Study of Yaozhou celadon and black wares (Tang dynasty), China Ceram. (1990) 57-62.

[6] F. Wang, Yaozhou Wares, Shaanxi University of Science and Technology Press, Shaanxi, 2000.

[7] K. Orvar, Notes on the wares from the Chiao Tso potteries: Ethnos: Vol 8, No 3, Ethnos. 8 (1943) 81-95.

[8] F. Zhang, The science of ancient Chinese ceramics, Shanghai People's Fine Arts Publishing House, Shanghai, 2000. 
[9] W. Li, H. Luo, J. Li, J. Li, J. Guo, Studies on the microstructure of the black-glazed bowl sherds excavated from the Jian kiln site of ancient China, Ceram. Int. 34 (2008) 1473-1480.

[10] W. Zhang, Scientific research on crystallization black glaze of high iron, Jingdezhen Ceramic Institute, 2010.

[11] Q. Ma, S. Xu, J. Wang, J. Yan, Integrated analysis of a black-glazed porcelain bowl in Tushan Kiln dated back to Song Dynasty, China, Mater. Chem. Phys. 242 (2020) 122213122223.

[12] C. Dejoie, P. Sciau, W. Li, L. Noé, A. Mehta, K. Chen, H. Luo, M. Kunz, N. Tamura, Z. Liu, Learning from the past: Rare $\varepsilon-\mathrm{Fe}_{2} \mathrm{O}_{3}$ in the ancient black-glazed Jian (Tenmoku) wares, Sci. Rep. 4 (2014) 4941-4949.

[13] B. Shen, P. Sciau, T. Wang, M. Brunet, J. Li, W. Lu, T. Zhu, Micro-structural study of colored porcelains of Changsha kiln using imaging and spectroscopic techniques, Ceram. Int. 44 (2018) 18528-18534.

[14] Z. Liu, C. Jia, L. Li, X. Li, L. Ji, L. Wang, Y. Lei, X. Wei, The morphology and structure of crystals in Qing Dynasty purple-gold glaze excavated from the Forbidden City, J. Am. Ceram. Soc. 101 (2018) 5229-5240.

[15] P. Sciau, C. Brouca-Cabarrecq, A. Pinto, Les glaçures de céramiques chinoises colorées au fer : un matériau historique à fort potentiel en science de la matière ?, Technè 47 (2019) 144-149.

[16] R. Wen, D. Wang, L. Wang, Y. Dang, The colouring mechanism of the brown glaze porcelain of the Yaozhou Kiln in the Northern Song Dynasty, Ceram. Int. 45 (2019) 1058910595.

[17] L. Wang, Y. Wang, M. Zhang, Q. Li, J. Wu, Z. Liu, L. Li, X. Wei, Three-dimensional microstructure of $\varepsilon-\mathrm{Fe}_{2} \mathrm{O}_{3}$ crystals in ancient Chinese sauce glaze porcelain revealed by focused ion beam scanning electron microscopy, Anal. Chem. 91 (2019) 13054-13061.

[18] J. Tuček, R. Zbořil, A. Namai, S. Ohkoshi, $\varepsilon-\mathrm{Fe}_{2} \mathrm{O}_{3}$ : An advanced nanomaterial exhibiting giant coercive field, millimeter-wave ferromagnetic resonance, and magnetoelectric coupling, Chem. Mater. 22 (2010) 6483-6505.

[19] T. Wang, P. Chen, M. Wang, Z. Sang, P. Zhang, F. Wang, P. Sciau, Micro-structural study of Yaozhou celadons (Tang to Yuan Dynasty): probing crystalline and glassy phases, J. Eur. Ceram. Soc. 40 (2020) 4676-4683.

[20] Ph. Sciau, Ph. Salles, C. Roucau, A. Mehta, G. Benassayag, Applications of focused ion beam for preparation of specimens of ancient ceramic for electron microscopy and synchrotron X-ray studies, Micron, 40 (2009) 597-604.

[21] Sciau, Ph. Transmission electron microscopy: emerging investigations for cultural heritage materials, in: Hawkes, P. W. (Ed.), In advances in imaging and electron physics, Elsevier, 2016, Vol. 198, pp 43-67.

[22] W. Li, W. Zhang, X. Lu, N. Zheng, H. Luo, Composition and structure of ancient Chinese rabbit hair black glaze, J. Build. Mater. 14 (2011) 329-334.

[23] Z. Thompson, S. Rahman, S. Yarmolenko, J. Sankar, D. Kumar, N. Bhattarai, Fabrication and characterization of magnesium ferrite-based PCL/aloe vera nanofibers, Materials. 10 (2017) 937-948.

[24] F. Naaz, H.K. Dubey, C. Kumari, P. Lahiri, Structural and magnetic properties of $\mathrm{MgFe}_{2} \mathrm{O}_{4}$ nanopowder synthesized via co-precipitation route, SN Appl. Sci. 2 (2020) 808-815. 
[25] Z.W. Wang, P. Lazor, S.K. Saxena, H.St.C. O'Neill, High pressure Raman spectroscopy of ferrite $\mathrm{MgFe}_{2} \mathrm{O}_{4}$, Mater. Res. Bull. 37 (2002) 1589-1602.

[26] N. Kolev, M.N. Iliev, V.N. Popov, M. Gospodinov, Temperature-dependent polarized Raman spectra of $\mathrm{CaFe}_{2} \mathrm{O}_{4}$, Solid State Commun. 128 (2003) 153-155.

[27] T. Ohsaka, F. Izumi, Y. Fujiki, Raman spectrum of anatase, $\mathrm{TiO}_{2}$, J. Raman Spectrosc. 7 (1978) 321-324.

[28] J. Lopez Sanchez, A. Serrano, A. Del Campo, M. Abuín, O. Rodríguez de la Fuente, N. Carmona, Sol-gel synthesis and micro-Raman characterization of $\varepsilon-\mathrm{Fe}_{2} \mathrm{O}_{3}$ micro- and nanoparticles, Chem. Mater. 18 (2015) 511-518.

[29] O.N. Shebanova, P. Lazor, Raman study of magnetite $\left(\mathrm{Fe}_{3} \mathrm{O}_{4}\right)$ : laser-induced thermal effects and oxidation, J. Raman Spectrosc. 34 (2003) 845-852.

[30] R. Gupta, A.K. Sood, P. Metcalf, J.M. Honig, Raman study of stoichiometric and Zndoped $\mathrm{Fe}_{3} \mathrm{O}_{4}$, Phys. Rev. B. 65 (2002) 104430-104437.

[31] C.P. Marshall, W.J.B. Dufresne, C.J. Rufledt, Polarized Raman spectra of hematite and assignment of external modes, J. Raman Spec. 51(2020) 1522-1529.

[32] P. Shi, F. Wang, J. Zhu, B. Zhang, T. Zhao, Y. Wang, J. Wang, Effect of phase separation on the Jian ware blue colored glaze with iron oxide, Ceram. Int. 44 (2018) 16407-16413.

[33] D.M. Sherman, The electronic structures of $\mathrm{Fe}^{3+}$ coordination sites in iron oxides: Applications to spectra, bonding, and magnetism, Phys. Chem. Miner. 12 (1985) 161-175.

[34] D.M. Sherman, T.D. Waite, Electronic Spectra of $\mathrm{Fe}^{3+}$ Oxides and Oxide Hydroxides in the Near IR to Near UV, Am. Mineral. 70 (1985) 1262-1269. 